\title{
O realismo maravilhoso em Cien Años de Soledad, de Gabriel García Márquez
}

\author{
Mariana Vieira ${ }^{\mathrm{i}}$
}

\begin{abstract}
RESUMO
$\mathrm{O}$ artigo revisa as diferenças e as semelhanças entre o gênero fantástico e o realismo maravilhoso. Nesse mesmo período, se explica a motivação de uso de técnicas realistas maravilhosas e a impossibilidade de sua classificação se dar pelo nome "realismo mágico". Após esta breve revisão, nos debruçamos sobre alguns aspectos que tornam nossa leitura de Cien Años de Soledad como a de um romance pertencente ao realismo maravilhoso, quais sejam: o narrador do romance e a cidade narrativa Macondo. Após esta análise, conclui-se que o romance incorpora a presença do mito do eterno retorno em sua construção espaço-temporal, o que pode dialogar, em nossa leitura, com a História da América Latina e alguns aspectos de sua recepção crítica.
\end{abstract}

Palavras-chave: Realismo Maravilhoso; Cien Años de Soledad; Gabriel García Márquez; Literatura latino-americana; Literatura e História.

\begin{abstract}
The article reviews the differences and similarities between the fantastic genre and the wonderful realism. In the same period, the motivation for wonderful realistic techniques and the impossibility of their classification are explained by the name "magical realism". After this brief review, we look at some aspects that make our reading of Cien Años de Soledad, such as that of a novel belonging to wonderful realism, namely: the narrator of the novel and the narrative city Macondo. After this analysis, it is concluded that the novel incorporates the presence of the myth of the eternal return in its spacetime construction, which can dialogue, in our reading, with the History of Latin America and some aspects of its critical reception.
\end{abstract}

Keywords: Wonderful Realism; Cien Años de Soledad; Gabriel García Márquez; Latin American literature; Literature and History.

\footnotetext{
${ }^{i}$ Possui graduação em Licenciatura em Letras pela Universidade do Estado do Amazonas. Foi bolsista de Iniciação Científica, durante 2015-2016, período em que desenvolveu a pesquisa "O realismo maravilhoso em Cien Años de Soledad", em 2016-2017 como voluntária em pesquisa sobre "O heterodiscurso em A cidade ausente, de Ricardo Píglia" e, em 2017-1018 em projeto acerca da presença de "O eu e o outro: um estudo da poesia de Borges a partir da teoria enunciativa bakhtiniana", pesquisas orientadas pela professora Dra. Juciane Cavalheiro. Durante os anos de graduação foi monitora em Estudos Temáticos de Literatura Portuguesa I, II e III. Neste mesmo período foi bolsista da Capes no Programa Institucional de Bolsas de Iniciação à Docência (PIBID). Atualmente, como mestranda do Programa de Pós-graduação em Letras e Artes (PPGLA-UEA), é membro do grupo de pesquisa Múltiplas Linguagens, Semiótica e Discurso na Contemporaneidade - SDiscon, no qual desenvolve pesquisa acerca do "Léxico de mulheres vítimas de violência na cidade de Manaus". Tem interesse em estudos acerca da construção da identidade e cultura latino-americana a partir de estudos em Literatura ibero-americana e Literatura pan-amazônica, sobretudo a partir de 1960.
} ORCID: https://orcid.org/0000-0003-1523-9519 | marianavicardoso@gmail.com 


\section{INTRODUÇÃO}

A transferência da capital do Brasil do Rio de Janeiro para Brasília, a primeira transmissão da televisão via satélite, a gravação do primeiro disco de The Beatles e, mais tarde, a construção do muro de Berlim, são informações presentes em livros e conteúdos midiáticos acerca da História dos anos 1960. Em contraponto, os impactos da Revolução Cubana são resumidos e o boom da literatura latino-americana é velado. Outrossim, em conformidade com Costa (2001), as obras latino-americanas publicadas ainda fazem parte do currículo do ensino básico e da maioria das ementas das graduações em Letras do Brasil.

Em $O$ nome da Rosa, Eco afirma que "é preciso reconhecer o mundo como um grande livro" (ECO, 2003, p. 31) e, para os hispano-americanos, a ótica realista maravilhosa tornou-se a melhor forma de realizar este reconhecimento. De acordo com Costa (2001), entre 1962 e 1968, há uma lista de romances latino-americanos, incluindo Cien Anõs de Soledad, que inovaram as perspectivas de escrita e recepção da literatura hispano-americana, ultrapassando o realismo, que era um lugar-comum daquele período:

\footnotetext{
Para muitos, o que motivou o boom, a nível comercial, além da qualidade literária das obras, foi o impulso das editoras (sobretudo europeias) e a irrupção da Revolução Cubana, que motivou inúmeros leitores, pelo mundo afora, a conhecer a literatura, a cultura e a história latino-americanas. (COSTA, 2001, p. 2)
}

Ainda que a obra de Gabriel García Márquez já tenha sido traduzida para a língua portuguesa, este trabalho se referirá a ela pelo seu título original e a partir de excertos feitos também na obra original. Conforme a citação acima, é possível compreendermos que, em meados de 1960, a produção literária ganha uma atenção comercial. Além disso, há durante estes anos a evidente necessidade de construir uma identidade autônoma, na qual a América Latina conseguisse expressar, através de sua própria ótica, o contexto político e cultural vivenciado desde sua formação até as influências da Revolução Cubana.

Assim, a revolução se transforma em um artigo de consumo, no qual "a América Latina entrou em moda. Descobriram que existiam romances latino-americanos suficientemente bons para serem traduzidos e equiparados ao resto da literatura 
mundial” (GARCIA MÁRQUEZ, 1989, p. 338). Deste modo, a partir de expressões estéticas, os artistas latino-americanos passam a comunicar suas visões de mundo. Durante este processo criativo, ocorre a eleição do realismo maravilhoso como um tipo de ficção, com bases muito relacionadas aos mitos, que funciona como uma leitura de mundo capaz de ultrapassar os limites da censura.

\footnotetext{
Esse tipo de ficção [a realista maravilha] apresenta uma busca de neutralização da censura, imposta pelos modelos culturais da época. [...] Esse movimento que vai da aceitação irrestrita de uma condição ocidental, para o retorno à qualificação utópica do Descobrimento (ou melhor, da 'invenção') da América, mostra, por um lado, o paradoxo que tem regido os anseios americanistas de promover a descolonização cultural. Mas, sua outra face significa que, nessa busca [...] contraditória da identidade do 'ser latinoamericano', o resultado é a consciência da diferença. (CHIAMPI, 2015, p. 67 e 112)
}

Nosso percurso se dará a partir da seguinte revisão: em um primeiro momento, detectaremos as diferenças e as semelhanças entre o gênero fantástico e o gênero realista maravilhoso. Nesse mesmo período, verificaremos a motivação de nossa identificação não ser o que, em outros momentos, a Crítica Literária nomeou como "realismo mágico". Após esta breve revisão, nos debruçaremos sobre o que definimos como realismo maravilhoso e sobre alguns aspectos que tornam nossa leitura de Cien Años de Soledad como a de um romance pertencente a este gênero, quais sejam: o narrador do romance; a cidade de Macondo e a presença do mito do eterno retorno em toda a narrativa.

\section{ENTRE O FANTÁSTICO E O REALISMO MARAVILHOSO}

Todorov (2010) define que o fantástico é um gênero que proporciona uma fronteira, uma linha de separação, entre o maravilhoso e o estranho. Estando no gênero fantástico, o leitor desfruta de uma incerteza sobre se deve acreditar na narrativa como sendo algo natural e comum ao contexto na qual está inserida ou se tudo nela constitui o sobrenatural e ficcional, o que são, respectivamente, as definições do gênero maravilhoso. O pacto entre os leitores e os narradores transcende diversas barreiras de outros tipos de ficção, pois até mesmo as personagens das narrativas fantásticas hesitam em acreditar nos acontecimentos narrativos, sendo, portanto, esta inquietação que será transmitida ao leitor. 
Todorov (2010) denomina como "leitor implícito" aquele que através das obras atinja a imagem mimética cujo autor desejara ao encadear seu discurso narrativo a partir do narrador. Por exemplo, ao ler um romance policial, espera-se que o leitor implícito questione e investigue a narrativa junto às personagens, pensando nas possibilidades de desfecho da obra. Sob esta ótica, o fantástico é, portanto, esta hesitação contínua, a contradição entre duas possibilidades que atingem tanto as personagens quanto o leitor.

Ao escolher uma das possíveis conclusões para explicar os acontecimentos do romance, saímos do gênero fantástico - que abrange esse paradoxo - e nos deparamos com o sobrenatural (gênero estranho) ou com um irreal, porém aceitável naquele ambiente (gênero maravilhoso). Todorov explica que este último é, muitas vezes, uma variedade de narrativas com as quais inicialmente acreditamos estar no universo fantástico, mas ao longo da construção do seu discurso aceitamos as ocorrências sobrenaturais expostas e nos encontramos no maravilhoso. Essa aceitação não se deve pelo fato de este tipo narrativo começar a possuir explicações verossímeis diante de nossa realidade, mas devido à narrativa continuar sem explicações. Em outras palavras, o leitor implícito passa a compreender que as personagens da narrativa não apresentam reações de equívoco e estranhamento aos elementos irreais, o que o encaminha à mesma postura, normalizando a irrealidade da narrativa sem racionalizá-los. Logo, "não é uma atitude para com os acontecimentos narrados que caracterizam o maravilhoso, mas a própria natureza desses acontecimentos" (TODOROV, 2010, p. 60).

Ainda que na Literatura, bem como nas demais expressões estéticas, os conceitos de verdade e de realidade não sejam questionados, já que a realidade literária é criada a partir de um acordo feito pelos artistas e fruidores, nossa ótica, a partir da leitura de Todorov (2010), é elucidar, neste ponto, como este acordo é feito. Deste modo, o (re)conhecimento do realismo maravilhoso se baseia no efeito discursivo da narrativa. A diferença entre este gênero e o fantástico consiste no encadeamento dos componentes naturais e sobrenaturais, pois, conforme Chiampi (2015), enquanto o fantástico se constrói através de conflitos entre os componentes, o realismo maravilhoso se desenvolve por meio destes componentes, para tornar tanto os naturais quanto os sobrenaturais parte constitutiva de sentido narrativo. É importante, ainda, não confundirmos esta causalidade do realismo maravilhoso com o maravilhoso puro, o que 
ocasionaria a hipótese de que o maravilhoso puro não desenvolve reações emocionais no leitor; quanto a isso Chiampi (2015) esclarece:

\begin{abstract}
Nos contos maravilhosos (com ou sem fadas), não existe o impossível, nem o escândalo da razão. Tapetes voam, galinhas põem ovos de ouro, cavalos falam [...]. O realismo maravilhoso, ao contrário, não foge aos realia pela indeterminação espaço temporal [...] tampouco explicita ou questiona a causalidade para eliminá-la. À diferença do maravilhoso, ela é restabelecida, e à diferença do fantástico, ela não é explícita, mas difusa. $\mathrm{O}$ regime causal do realismo maravilhoso é ditado pela descontinuidade entre causa e efeito. Como já observou Borges: [...] 'a causalidade é mágica'. (CHIAMPI, 2015, p. 60 , grifo da autora)
\end{abstract}

Ao colocar no mesmo plano narrativo os componentes naturais e sobrenaturais, o realismo maravilhoso produz essa "causalidade mágica" através do encantamento no qual insere o leitor, visto que esta aproximação do real e do irreal gera sentido para o que, no fantástico, causava medo, conflito e/ou inquietação. Em outras palavras, enquanto o fantástico proporciona estranhamento, "o realismo maravilhoso desaloja qualquer efeito emotivo de calafrio, medo ou terror sobre o evento insólito" (CHIAMPI, 2015, p. 59).

Ao recepcionar este estranhamento, o leitor de literatura fantástica hesita sobre a motivação que ocasionou a presença do sobrenatural na narrativa e, como constatamos, esta hesitação também é característica das personagens deste movimento literário. Já no realismo maravilhoso, o leitor não se questiona quanto à possibilidade de os acontecimentos sobrenaturais serem reais ou irreais na narrativa, pois o seu discurso persuade e produz o encantamento aos personagens e, consequentemente, ao leitor. Podemos concluir, portanto, que a literatura fantástica e realista maravilhosa se constituem a partir do mesmo princípio de percepção e se diferenciam, ainda, neste aspecto da construção de seus discursos e de suas recepções, pois "o realismo maravilhoso se qualifica pela relação entre o efeito de encantamento (o discurso) e o relato" (CHIAMPI, 2015, p. 59).

Adensando ainda mais a nossa ótica acerca do realismo maravilhoso, levemos em conta que, através de nossos conhecimentos e experiências, possuímos um acervo mental enquanto leitores e com ele podemos referenciar os conceitos coligados ao mundo real às nossas noções de verdade. Por este motivo, essa espécie de pacto, antes comentada, entre o discurso realista maravilhoso e o leitor, cujo acordo adere como verossímil os componentes reais e fantasiosos, ocasiona a ausência de hesitações e a 
vivência de novas verdades dentro da narrativa. Essa mesma técnica ocorre na narrativa mítica e, por isso, para Chiampi (2015, p. 13), o mito funciona como primeiro ancestral do realismo maravilhoso, pois seu caráter envolve o discurso persuasivo e as motivações relacionadas ao sobrenatural.

Ainda que o realismo maravilhoso tenha origem na literatura do maravilhoso puro, os fenômenos sobrenaturais do primeiro não são apresentados em um espaço ou tempo da mesma natureza. Ao contrário, esses fenômenos são narrados em ambientes naturais ao conhecimento do leitor, ou seja, uma ótica realista é acrescida nesse tipo de discurso artístico. Ainda assim, o sobrenatural exposto não substitui a realidade narrada e, por este motivo, não é coerente inserir este tipo de narrativa ao maravilhoso puro. Chiampi (2015) explica que a assimilação da proximidade entre o natural e o sobrenatural não deriva da narrativa maravilhosa dentro do discurso realista e sim do rompimento da causalidade característica neste discurso. Além disso, destaquemos, ainda, o motivo ao qual empregamos e reconhecemos a existência do realismo maravilhoso e não do realismo mágico:

\footnotetext{
Maravilhoso é termo já consagrado pela Poética e pelos estudos críticoliterários em geral, e se presta à relação estrutural com outros tipos de discursos (o fantástico, o realista). Mágico, ao contrário, é termo tomado de outra série cultural e acoplá-lo a realismo implicaria ora uma teorização de ordem fenomenológica (a 'atitude do narrador'), ora de ordem conteudística (a magia como tema). (CHIAMPI, 2015, p. 43)
}

Precisaremos agora, sob a ótica realista maravilhosa, analisar alguns aspectos da obra que alcançou o prêmio Nobel de literatura em 1982, Cien Años de Soledad, com a finalidade de encontrarmos algumas ferramentas utilizadas na construção dessa narrativa e os possíveis efeitos destes engendramentos no que concerne à recepção da obra.

\section{O NARRADOR DE CIEN AÑOS DE SOLEDAD}

Chiampi (2015) aponta que há narrativas que utilizam o realismo maravilhoso como plano de fundo, mas dentre elas nenhuma explora tanto este gênero como o romance de Gabriel García Márquez, Cien Años de Soledad. Nosso primeiro destaque é que, durante todo o romance, o narrador modifica a relação pragmática do leitor com o 
aspecto da maravilha e, além disso, também alterna essa relação de sentido para com a realidade em si. Algumas passagens podem exemplificar claramente esta recorrência. Por exemplo, a insônia que se alastrou em Macondo:

\begin{abstract}
Habían contraído, en efecto, la enfermedad del insomnio. [...] Al principio nadie se alarmó. Al contrario, se alegraron de no dormir, porque entonces había tanto que hacer en Macondo que el tiempo apenas alcanzaba. [...] Cuando José Arcadio Buendía se dio cuenta de que la peste había invadido el pueblo, $[\ldots]$ y se acordaron medidas para impedir que el flagelo se propagara a otras poblaciones de la ciénaga. [...] Tan eficaz fue la cuatenena, que llegó el día en que la situación de emergencia se tuvo por cosa natural, y se organizó la vida de tal modo que el trabajo recobró su ritmo y nadie volvió a preocuparse por la inútil costumbre de dormir. (GARCìA MÁRQUEZ, 2007, p. 57-59)
\end{abstract}

E, como outro exemplo, a ascensão de Remedios, la bella, ao céu:

Amaranta sintió que un delicado viento de luz Le arranco las sábanas de las manos y las desplegó en toda su amplitud. Amaranta sintió un temblor misterioso en los encajes de sus pollerinas [...], en el instante en que Remedios, la bella, empezaba a elevarse. Úrsula, ya casi ciega, fue la única que tuvo serenidad para identificar la naturaleza de aquel viento irreparable, y dejo las sábanas a merced de la luz, viendo a Remedios, la bella, que le decía adiós con la mano. [...] La mayoría creyó en el milagro, y hasta se encendieron velas y se rezaron novenarios. (GARCÍA MÁRQUEZ, 2007, p. 271-272)

Assim, a função do narrador preconiza a reação do leitor. No realismo maravilhoso, essa função destina-se em encadear um discurso no qual o encantamento seja possibilitado através da construção deste relato na própria narrativa. Sob essa funcionalidade, o narrador adquire voz através de sua performance na estruturação do encantamento e, em seu decorrer, realiza escolhas de como organizar os acontecimentos reais e irreais que designam o foco e eclodem na performance como voz narrativa. Em conformidade com Chiampi (2015), este ciclo é composto por dois movimentos: 1) performance na estruturação e 2) performance como voz, que constituem a análise narrativa e constroem a composição realista maravilhosa.

Ademais, de acordo com a mesma linha de análise, podemos apontar as estratégias narrativas contidas no romance para introduzir relatos como "Muchos años después, frente al pelotón de fusilamiento...”. Tais estratégias, que levam o leitor a uma visão futura, relembram que o narrador é onisciente, sabe da narrativa até um certo ponto e este ponto está à frente daquele que a lê. Contudo, quando a narrativa se aproxima do desfecho, ocorre uma inversão na qual o narrador vivencia, na companhia 
da personagem Aureliano Babilônia, as últimas vezes em que os pergaminhos serão lidos, passando de um narrador-deus a um narrador-personagem que acompanha a narrativa e depende dela, não sendo capaz de interferir ou modificar seu curso.

\begin{abstract}
Macondo era ya un pavoroso remolino de polvo y escombros centrifugados por la cólera del huracán bíblico, cuando Aureliano salto once páginas [...], y empezó a descifrar el instante que estaba viviendo, descifrándolo a medida que lo vivía, profetizándose a sí mismo en acto de descifrar la última página de los pergaminos, como si se estuviera viendo en un espejo hablado. [...] Sin embargo, antes de llegar al verso final ya había comprendido que no saldría jamás de ese cuarto, pues estaba previsto que la ciudad de los espejos (o los espejismos) sería arrasada por el viento y desterrada de la memoria de los hombres en el instante en que Aureliano Babilonia acabara de descifrar los pergaminos, y que todo lo escrito en ellos era irrepetible desde siempre y para siempre [...] (GARCÍA MÁRQUEZ, 2007, p. 470, 471)
\end{abstract}

Dentro da escola realista maravilhosa há, de acordo com Chiampi (2015), uma técnica intitulada barroquismo descritivo, classificada como um tipo de narrativa que percorre um caminho cíclico que, ao naturalizar o irreal, ficciona o real:

É o resultado duplo da construção em abismo de Cien Años e que a forma de percepção apontada corresponde a uma só possibilidade dessa técnica - tão vivificada no período barroco e revivificada no neobarroco hispanoamericano. Sendo que o texto dos manuscritos de Melquíades reproduz especularmente o texto do romance inteiro, a confusão entre o mundo do leitor e o mundo do livro convela outro efeito peculiar [...]: a 'ficcionalização da realidade'. (CHIAMPI, 2015, p. 84)

Nesta linguagem narrativa destacam-se peculiaridades no encadeamento do discurso para produzir a tensão e articular a ficção. É muito frequente, por exemplo, a técnica de proliferação dos significantes, em que a distorção da linearidade do enunciado faculta singular combinação das funções de comunicação, como, por exemplo, a deformação da linearidade da narrativa, acerca do final de Meme, anunciando seu futuro e não apresentando novas passagens sobre a personagem:

Meme le tomó la mano y se dejó llevar. La última vez que Fernanda la vio [...], acababa de cerrarse detrás de Ella el rastrillo de hierro de la clausura. Todavía pensaba en Mauricio Babilonia. En su olor de aceite y su ámbito de mariposas, y seguiría pensando en él todos los días de su vida, hasta la remota madrugada de otoño en que muriera de vejez, con sus nombres cambiados y sin haber dicho nunca una palabra, en un tenebroso hospital de Cracovia. (GARCÍA MÁRQUEZ, 2007, p. 337) 
Segundo Chiampi (2015), este tipo de discurso ressalta justamente o contexto hispano-americano que tem um sentimento de independência, acompanhado de um governo moldado pela herança colonial, uma identidade complexa e a inferioridade acentuada por outros países. Assim, a narrativa produz esta sensação identitária do "pode vir a ser" para se tratar do real com o objetivo de não haver censuras quanto às temáticas abordadas, pois "a introdução de elementos sobrenaturais é um recurso para evitar esta condenação, este silenciamento de governos autoritários" (TODOROV, 2010, p. 168).

Estes elementos, narrados em um ambiente realista, tornam a obra surpreendente e produzem o encantamento de maneira plácida e discreta. Através do discurso realista maravilhoso, naturaliza-se o tapete voador trazido pelos ciganos; a imagem da menina Rebeca carregando a mortalha de seus pais; a peste da insônia e o esquecimento do nome das coisas, dos seres e de suas utilidades, levando os moradores de Macondo a escreverem no cachaço da vaca "Esta es la vaca, hay que ordeñarla todas las mañanas para que produzca leche y a la leche hay que hervila para mesclarla con el café y hacer café con leche" (GARCÍA MÁRQUEZ, 2007, p. 60), mesmo sabendo que após algum tempo até as letras seriam esquecidas.

Ainda acerca destes elementos sobrenaturais, aceitos pelo leitor através deste acordo narrativo do encantamento, pode-se destacar a loucura que leva o patriarca José Arcádio Buendía a ser amarrado em uma castanheira, a esquecer seu idioma, falando apenas em latim, e a sua morte com a garoa de "minúsculas flores amarillas" (GARCÍA MÁRQUEZ, 2007, p. 166); o relacionamento de Remédios Moscote e Aureliano, a morte desta personagem feminina, as trinta e duas guerras sem vitória de seu marido, bem como suas premunições; a aparição, em épocas distintas da guerra, de mulheres com meninos que diziam ser filhos do Coronel Aureliano Buendía, cuja paternidade não foi questionada, por todos terem o mesmo olhar solitário do pai e, mais tarde, o extermínio dos dezessete Aurelianos, mortos com tiros em suas testas por assassinos anônimos; a velhice do Coronel Buendía e seus peixinhos de ouro.

Poderíamos continuar e citar diversos exemplos que constituem aspectos realistas maravilhosos em Cien Años de Soledad, exemplos que transferem a narrativa ao patamar do mito. Para pensarmos em aspectos míticos, relembremos que, de acordo com Eliade (1989), a literatura é fruto do mito e até hoje utilizamos protótipos 
discursivos relacionados ao mito em diferentes gêneros, entre os quais Chiampi (2015) aponta o realismo maravilhoso, pois ele proporciona espaço propício para a magia mitológica sem se tornar uma narrativa irreal. Tal concepção reverbera que o mito é compreendido desde as sociedades primitivas como uma história verdadeira e sagrada devido à sua importância em expressar os temores e questionamentos das sociedades. Logo, compreende-se que "ao começar o novo século, já era hora (...) de desembaraçar o percurso da utopia americana do mito pessimista de nossa inferioridade cultural e narrar nossos próprios mitos, ainda que os chamemos de literatura" (CHIAMPI, 2015, p. 112). Em conformidade com esta perspectiva, vejamos, a seguir, alguns aspectos acerca de Macondo, a cidade em que o romance acontece.

\section{MACONDO: UMA CIDADE MÍTICA}

De acordo com Simioni (2009), ao adentrar na novela Cien Años de Soledad, é possível observar que cada período da narrativa de Macondo, desde sua fundação até sua modernização e declínio, se articulam a uma fase da História da América Latina. Sob esta perspectiva, a aldeia fictícia representa na obra a colonização e a exploração de diversas nações sob o território hispano-americano. Chiampi (2015) acrescenta que a população latino-americana almejava relatar, sob a sua própria ótica, o contexto político e psicossocial de 1960, visto que, conforme salienta Simioni (2009), os livros de história e todos os códigos que regiam os sistemas sociais ainda eram estrangeiros e transmitiam o viés de menosprezo à população colonizada.

Relembremos que Macondo é fundada por José Arcádio Buendía que estava inquieto pela presença do fantasma de seu inimigo, Fulgêncio Aguilar, assassinado após uma discussão em que a masculinidade de José Arcádio foi colocada em questão. Com o objetivo de se ver livre da presença do morto, o jovem patriarca parte em busca de uma nova região, acompanhado por sua esposa Úrsula Iguarán e por alguns jovens casais. Após vinte e seis meses vagando, período em que nasce o primeiro filho do casal, fundam a aldeia no lugar em que estavam. O narrador do romance afirma que tudo era tão novo que não haviam nomeado os objetos e era necessário apontar para eles e refletir sobre como os chamariam. 
Nesta ótica, Macondo representa um espaço sem tempo e sem nome para as coisas; Macondo é o princípio e se realiza como um presente contínuo. Hutcheon (1991) relaciona a noção de tempo e a nomeação das eras, por exemplo, a uma espécie de complexo de Adão. A nomeação de todos os seres viventes, até mesmo Eva - "E o homem chamou à mulher Eva" (Genesis 3:20) -, é marcada no mito adâmico como uma necessidade humana para que houvesse o pertencimento a partir do reconhecimento de si e, após isso, a anunciação de um futuro apagamento deste mesmo eu, de acordo com Derrida (2011, p. 43). Assim, se não houvesse nenhum ser vivo que contasse a sua própria destruição, tal qual os humanos, como haveria tempo e a concepção de Antiguidade ou Modernidade, por exemplo? Tal questionamento pode parecer frágil e irrelevante, mas torna-se mais consistente se, a partir dele, refletirmos sobre os aspectos que os sujeitos valorizaram ou excluíram ao longo de sua relação com as vertentes do tempo.

De acordo com Bergson (1999), o presente existe para o sujeito, já que o sujeito sempre existe no presente. Assim, não faz sentido afirmar a existência de um indivíduo no passado, pois, no passado, existia-se paradoxalmente no presente. Do mesmo modo, quando estivermos no futuro o nomearemos de presente. Até mesmo em um processo de memorialização, por exemplo, o recordar é colocado em um estágio de presente, de vivência. Desta forma, torna-se impossível a ida ao passado e torna-se inviável a recordação fiel de determinado evento, pois, em conformidade com Beatriz Sarlo (2012), a memória coloniza o passado a partir de sentimentos e perspectivas do próprio sujeito.

Para além disso, quando um indivíduo se imagina no futuro, a imaginação é um estágio do presente. Então, Bergson (1999) conclui que só o presente existe. Assim, o momento de escrita de uma pesquisa como esta era o presente enquanto as letras se colocavam neste papel, mas, definitivamente, agora este processo já está no passado, e se atualizará a um estágio de presente enquanto são lidas, fazendo - ou não - sentido, em conformidade com este tempo presente e não em relação ao passado de seu processo de escrita, seu presente primordial.

José Arcádio, em Cien Años de Soledad, se tornou uma espécie de conselheiro que, apesar da juventude, instruía nos setores de agricultura, criação de animais, relacionamento com os filhos e organizava a disposição das casas de forma justa 
tornando a sua moradia um modelo a ser seguido pela aldeia. Simioni (2009) explica o primeiro traço mítico importante neste contexto, denominando a sociedade de Macondo de utópico-diaspórica:

\begin{abstract}
A significação que envolve o termo diáspora surge, primeiramente, para denominar o fluxo migratório percorrido pelo povo judeu a uma fuga da escravidão do Egito. Sob a liderança de Moisés, o povo escolhido parte em busca de liberdade, da almejada terra prometida, deixando para trás todo o sofrimento vivido no cativeiro da grande 'Babilônia'. [...] Associando a fase de fundação de Macondo ao período colonial da América Latina, em relação a como a maioria dos centros urbanos se formaram, nota-se que a cidade fictícia não obedece ao curso dos espanhóis [...]. Temos, no entanto, a tentativa de criar uma comunidade livre, sem divisões sociais, tendo apenas a família Buendía, na figura de José Arcádio Buendía, como um mediador da busca por iguais condições entre habitantes. (SIMIONI, 2009, p. 158-159)
\end{abstract}

Pouco tempo depois de sua fundação, a narrativa afirma que Macondo estava desequilibrada e longe de seu estado pacífico inicial. Isso ocorre graças à chegada dos ciganos com suas descobertas advindas de diversos países. A agitação cigana provocava nos residentes de Macondo "um pânico de alvoroçada alegria", tornando-os "perdidos nas suas próprias ruas" e influenciados pela nova atração. Os ciganos continuaram a visitar o povoado, levando consigo, anos mais tarde, o filho primogênito dos Buendía, o que levou Úrsula a sair do povoado para procurar pelo filho, voltando após meses com vários novos moradores para a cidade. Assim, a chegada dos ciganos, de certo modo, representa uma colonização para Macondo, uma retirada do presente contínuo mítico.

A saída de Úrsula também representa uma busca por territórios desconhecidos e a sequência do retorno da matriarca, com novos moradores para cidade, pode ser lida como um adendo à representação de uma miscigenação e nova formação social. Sob esta ótica, Macondo representa as cidades latino-americanas que,

desde sua época intocada pela presença europeia, [...] passa pela hifenização populacional propiciada pela convivência entre índios, castelhanos e ciganos, configurando-se numa nova formatação social resultante desse entrecruzamento (SIMIONI, 2009, p. 160).

\title{
CONSIDERAÇÕES FINAIS
}

Mircea Eliade (2013) aponta que o tempo mítico pode ser definido como aquele que vai além do tempo concreto, porque o ultrapassa e se caracteriza como sagrado por 
ser cíclico, retornando sempre aos apontamentos e situações vivenciadas. Aprofundando ainda mais os conceitos estabelecidos, Eliade (2013) comenta que as sociedades primitivas dividiam o tempo em profano, como aquele que obedece à linearidade a qual os seres humanos estão habituados no mundo moderno, e em sagrado, cujo aspecto periódico é repetitivo e dominante. Dentro dessa segunda classificação do tempo, há as dicotomias em que este espaço-temporal pode ser infinito ou limitado, contínuo ou periódico. Ao longo de nossa leitura, representamos algumas concepções de tempo a partir do narrador de Cien Años de Soledad, assim como realizamos uma leitura do espaço a partir da construção de Macondo.

Retornando aos pergaminhos da narrativa de Cien Años, é possível observarmos que eles estão escritos em tempo linear, mas as narrativas nos trazem características repetitivas, ou seja, que retornam ao que já foi apresentado. Mesmo assim, o leitor, através do processo de encantamento, adere a este movimento cíclico e até o reconhece ao longo da leitura sem temores ou questionamentos. Devido ao discurso realista maravilhoso, ao final da narrativa, verificamos que este tempo é sagrado e limitado, pois: "todo lo escrito en ellos era irrepetible desde siempre y para siempre, porque las estirpes condenadas a cien años de soledad no tenían una segunda oportunidad sobre la tierra" (GARCÍA MÁRQUEZ, 2007, p. 471).

Como exemplo das repetições contidas no romance, podemos apontar o desejo amoroso desfrutado por Úrsula Iguarán e o patriarca José Arcádio Buendía, que eram primos, e, mais tarde, este mesmo desejo é vivenciado por Amaranta e o sobrinho Aureliano José; similar afeto é representado por Amaranta e José Arcádio, filho de Fernanda e Aureliano; o mesmo acontece com Amaranta Úrsula e Aureliano Babilônia e, até mesmo, José Arcádio, filho de Úrsula, e Rebeca, que são criados como irmãos e depois se casam. Ademais, as repetições se tornam ainda mais evidentes a partir dos nomes e dos fantasmas que assombram os diferentes personagens que tenham o mesmo nome, como Melquíades que aparece diversas vezes para os Aurelianos.

Ainda sobre a repetição dos nomes, eles guardam similaridades que envolvem o teor mítico porque se equiparam com as características das personagens. Conforme Úrsula observara, "los Aurelianos eran retraídos, pero de mentalidad lúcida, los José Arcadio eran impulsivos y emprendedores, pero estaban marcados por un signo trágico" 
(GARCÍA MÁRQUEZ, 2007, p. 211). Simioni (2009) esclarece a representatividade que pode encadear esta narrativa com a realidade latino-americana:

\begin{abstract}
O movimento circular da história da cidade fictícia da narrativa de García Márquez remete à condição da parcela territorial descoberta pelas naus ibéricas séculos atrás que, mesmo após um suposto rompimento com suas antigas metrópoles, continua alimentando modalidades de domínio, agora estabelecidas de maneira indireta. [...] Em meio a esse constante processo de formação e deformação da cultura, a questão identitária surge como um problema. [...] Apresentando a solidão como antinomia da solidariedade (...), mais especificamente em se tratando da composição dos membros da família Buendía, como uma ilustração notável da falta desse sentimento de cooperação [...] reflete, entre outros modos representativos do romance, a conotação política do termo solidão. (SIMIONI, 2009, p. 162, 172)
\end{abstract}

Além dessa representação latino-americana, em diversos períodos da narrativa é possível destacar a questão da formação e deformação da cultura como alegorias recorrentes do romance. Um exemplo disso está na afirmação de Úrsula sobre a importância de recepcionar bem os migrantes que chegavam a Macondo, submetendo aos moradores como servos de seus visitantes:

\footnotetext{
'Hay que hacer carne y pescado', ordenaba a las cuatro cocineras [...] 'Hay que hacer de todo porque nunca se sabe qué quieren comer los que vienen'. $\mathrm{Al}$ almuerzo, la casa trepidaba con un alboroto de mercado, e los sudorosos comensales, que ni siquiera sabían quiénes eran sus anfitriones, irrumpían en tropel para ocupar los mejores puestos en la mesa [...]. (GARCÍA MÁRQUEZ, 2007, p. 263)
}

Eliade (2013) define que os mitos cuja temática seja acerca da representação da criação são denominados mitos cosmogônicos. Ao analisar a narrativa de Cien Años, podemos concluir que há na obra um mito de origem, ou seja, a fundação de Macondo e da família Buendía: a forma como os objetos e seres passaram a ter nome; o crescimento da aldeia; o desenvolvimento de costumes e crenças até o mito de sua extinção, seu apocalipse. Estes tipos de mitos, ainda de acordo Eliade (2013), são comumente encontrados em narrativas de cunho sagrado, elencadas pelas sociedades como explicações para a origem e funcionalidade do mundo e de seus seres.

Como exemplo dessa construção mítica, podemos citar o trecho narrativo de quando Aureliano, filho de José Arcádio e Úrsula Iguarán, inicialmente não compreendia o motivo de seu sogro, Apolinar Moscote, providenciar soldados armados para vigiar as eleições em Macondo. Aureliano sabia que os moradores não 
apresentavam intenções ambiciosas acerca da política, mas, a partir daquele momento, há a primeira introdução a este contexto, a qual Simioni (2009) aponta como sendo uma introdução a uma nova estrutura social.

\begin{abstract}
Esse evento alude para um novo momento da configuração social da cidade, que agora passa a conviver com a presença de linhas ideológicas que divergem no que diz respeito à forma de constituição e exercício político na região. [...] Desse modo, denota-se que no caso de Macondo, em consonância à visão de Foucault, deparamo-nos com o conflito bélico armado como um prolongamento de políticas que não deram certo. (SIMIONI, 2009 p. 161)
\end{abstract}

Por ser a entrada para um sistema ideológico-político, configura-se, nesta parte da narrativa, uma explicação para a origem de um costume na sociedade, bem como a caracterização do mito cosmogônico (ELIADE, 2013). Chiampi (2015) nos esclarece o porquê de, no discurso da narrativa, haver verossimilhança em Aureliano Buendía representar o papel inicialmente inocente e desinteressado acerca da política, para depois tornar-se um coronel, que promoveria trinta e duas guerras e não venceria nenhuma, sofrendo quatorze atentados e saindo ileso de todos, assim como setenta e três tentativas de prisão e um pelotão de fuzilamento, tornando-se, após morto de velhice, uma lenda em quem apenas as personagens Aureliano Babilônia e Gabriel Márquez acreditavam. Vejamos:

O que nos leva a assentir com os enunciados destonalizados de Cien años de soledad, como aquele que diz ter o Coronel Aureliano Buendía participado de 32 guerras civis e tê-las perdido todas? Essas interrogações genuínas já superam o bloqueio da "não conformidade da significação do real" (não se questiona se o Outro Sentido é ou não verdadeiro no realismo maravilhoso) e situam a questão do verossímil no quadro de uma situação de performance narrativa [...] é porque a sua seriedade (e autoridade) é para deslocar um sistema estável de referências radicam num pacto de assentimento entre o narrador e o narratório. E este pacto [...] do discurso realista maravilhoso não se define pelo nível dos enunciados produzidos [...] mas no plano das substâncias. (CHIAMPI, 2015, p. 165, grifo da autora)

Ademais, assim como nos relatos da Bíblia Cristã e da mitologia grega e chinesa, o tempo de Cien Años de Soledad adere a uma dicotomia: em uma vertente, há o seguimento de um pergaminho de cem anos, e em outra, há a narração do romance, ambos sempre estão em tempo presente. O narrador afirma que o primeiro da estirpe está amarrado a uma árvore e o último está sendo comido pelas formigas, sendo esta uma característica também ritual, na qual todos os seus representantes envolvidos 
desenvolvem, ao mesmo tempo, funções similares que se interligam e completam na existência de um tempo sagrado. Há, assim, o estabelecimento de um tempo do mito "porque las estirpes condenadas a cien años de soledad no tenían una segunda oportunidad sobre la tierra." (GARCÍA MÁRQUEZ, 2007, p. 471). Portanto,

\footnotetext{
O tempo sagrado é reversível, ou seja, a festa religiosa não é simples comemoração, mas a ocasião pela qual o evento sagrado que teve lugar no passado mítico, acontece novamente. Caso contrário, a semente não brotará da terra, a mulher não será fecundada, a árvore não dará frutos, o dia não sucederá à noite. Sem os ritos, é como se os fatos naturais descritos não pudessem se concretizar. (ARANHA \& MARTINS, 2009, p. 27)
}

Além desta dicotomia no espaço temporal da narrativa, há, ainda, o dormitório de Melquíades cuja dicotomia não abrange o tempo característico deste ambiente, visto que, nele, as personagens não sentem fome, como José Arcádio Segundo e Aureliano Babilônia, ficando por dias sem sair do quarto para comer ou beber. Assim, a presença dos pergaminhos, e por vezes do próprio cigano, cria uma característica mítica cosmogônica, pois conforme aponta Eliade (2013), há nesses trechos um espaço dedicado ao Ente Divino, cuja função é guardar estes mistérios e conceder comunicações a alguns seres humanos que funcionam como médiuns em transes nos quais o humano entra em um estado vegetativo e de clarividência.

Além das características supracitadas, há entre as últimas gerações dos Buendía a relação entre Maurício Babilônia e Meme, cujo filho, Aureliano Babilônia, comete o que Úrsula acreditava ser um pecado: uniu-se a Amaranta Úrsula sem saber que esta era sua tia. Desta união nasce, portanto, o último ser da estirpe, uma criança com rabo de porco.

Com base na perspectiva de Eliade (2013), que afirma que todos os dilúvios e catástrofes presentes nos mitos são devido a falhas nos rituais, compreende-se que os pergaminhos eram uma espécie de manual que poderia ter servido como profilaxia para a vida dos Buendía; mas, ao não ter sido realizado este intento, cumpre-se a profecia destinada àqueles cuja solidão dos ensinamentos os extingue. $\mathrm{O}$ cuidado narrativo em criar este discurso mítico é tão evidente que há a alegoria do sobrenome Babilônia nas três últimas gerações dos Buendía. Babilônia, que vem do grego "Babel”, significa "confusão de línguas", "grande confusão" e aponta, na mitologia cristã, a cidade que mais sofrerá no apocalipse. Esta ótica, aplicada ao povo latino-americano, pode ser lida 
como a preocupação e crítica acerca da falta de informação da população sobre sua própria história e cultura, inferiorizando-se e alienando-se como as personagens da narrativa.

"A leitura tem a ver com empatia, projeção e identificação" (COMPAGNON, 2001, p. 143) e essa perspectiva de reconhecimento é aderida pelo discurso realista maravilhoso em Cien Años de Soledad. A solidão compartilhada por todos os Buendía e o silêncio de cada cidadão de Macondo diante de um dilúvio ou de diversas guerras são salientados através de personagens tão repetitivas quanto inesquecíveis. García Márquez não apenas projetou uma identidade latino-americana, mas também acrescentou a ela as explicações que lhe eram pedidas criando alegorias míticas que reverberam em seu discurso ao Nobel: “A América Latina não quer nem tem porque ser um peão sem rumo ou decisão, nem tem nada de quimérico que seus desígnios de independência e originalidade se convertam em uma aspiração ocidental" (GARCÍA MÁRQUEZ, 2015, p. 367). Nossa intenção com esta breve leitura é, em verdade, uma contribuição, ainda que parcial, para as possibilidades críticas pós-coloniais e as continuidades em estudos culturais, míticos, filosóficos e historiográficos vindouros.

\section{Referências}

ARANHA, Maria Lúcia de Arruda; MARTINS, Maria Helena Pires. Filosofando: Introdução à filosofia. São Paulo: Moderna, 2009.

BERGSON, Henri. Matéria e memória: ensaio sobre a relação do corpo com o espírito. Trad. Paulo Neves. São Paulo: Martins Fontes, 1999.

COMPAGNON, Antoine. O demônio da teoria: leitura e senso comum. Trad. Clarice Paes Barreto Mourão. Belo Horizonte: Editora da UFMG, 2006.

UFMG, 2009.

Literatura pra quê. Trad. de Laura Taddei Brandini. Belo Horizonte: Editora

CHIAMPI, Irlemar. O realismo maravilhoso: forma e ideologia no romance hispanoamericano. São Paulo: Perspectiva, 2015.

COSTA, Adriane Vidal. Os intelectuais, o boom da literatura latino-americana e a Revolução Cubana. In: Anais do XXVI Simpósio Nacional de História - ANPUH, São Paulo, 2001. 
DERRIDA, Jacques. O Animal que logo sou (a seguir). Trad. Fábio Landa. 2. ed. São Paulo: Unesp, 2011.

ECO, Umberto. O nome da rosa. Trad. Aurora Fornoni Bernardini. Rio de Janeiro: Nova fronteira S/A, 1986.

ELIADE, Mircea. Aspectos do mito. Lisboa: Edições 70, 1989. O mito do eterno retorno. Lisboa: Edições 70, 1969. . Mito e Realidade. Trad. Pola Civelli. São Paulo: Perspectiva, 2013.

HALL, Stuart. A identidade cultural na pós-modernidade. Trad. Tomaz Tadeu da Silva e Guacira Lopes Louro. Rio de Janeiro: DP\&A editora, 2006.

HUTCHEON, Linda. Uma teoria da paródia: ensinamentos das formas de artes do século XX. Trad. Teresa Louro Pérez. Rio de Janeiro: Edições 70, 1985. Disponível em: https://kupdf.net/download/hutcheon-linda-uma-teoria-da-par-oacutedia_58cda092dc0d60f85bc3466b_pdf Acesso em: 26 de novembro de 2020.

MÁRQUEZ, Gabriel García. As históricas entrevistas da Paris Review II. Seleção Marcos Maffei. Trad. Marcos Maffei. São Paulo: Companhia das Letras, 1989.

Cien años de soledad. Barcelona, Espanha: Real Academia Española, 2007.

SIMIONI, Ronan. Cem anos de Mitos, imperialismo e solidão: Macondo e a (des)construção identitária latino-americana. Santa Maria, RS: Disc. Scientia. Série: Artes, letras e comunicação, v. 10, n. 1, p. 147-174, ISSN 1676-5001, 2009.

TODOROV, Tzvetan. Introdução à literatura fantástica. Trad. Maria Clara Castello. São Paulo: Perspectiva, 2010. 